\title{
Transport timescales and tracer properties in the extratropical UTLS
}

\author{
P. Hoor ${ }^{1}$, H. Wernli ${ }^{2}$, M. I. Hegglin ${ }^{3}$, and H. Bönisch ${ }^{4}$ \\ ${ }^{1}$ Institute for Atmospheric Physics, University of Mainz, 55128 Mainz, Germany \\ ${ }^{2}$ Institute for Atmospheric and Climate Sciences, Federal Institute of Technology (ETH), Zürich \\ ${ }^{3}$ Department of Physics, University of Toronto, Toronto, Canada \\ ${ }^{4}$ Institute for Atmospheric and Environmental Sciences, Goethe University, Frankfurt/Main, Germany
}

Received: 3 May 2010 - Published in Atmos. Chem. Phys. Discuss.: 20 May 2010

Revised: 3 August 2010 - Accepted: 5 August 2010 - Published: 25 August 2010

\begin{abstract}
A comprehensive evaluation of seasonal backward trajectories initialized in the northern hemisphere lowermost stratosphere (LMS) has been performed to investigate the factors that determine the temporal and spatial structure of troposphere-to-stratosphere-transport (TST) and it's impact on the LMS. In particular we explain the fundamental role of the transit time since last TST $\left(t_{\mathrm{TST}}\right)$ for the chemical composition of the LMS. According to our results the structure of the LMS can be characterized by a layer with $t_{\mathrm{TST}}<40$ days forming a narrow band around the local tropopause. This layer extends about $30 \mathrm{~K}$ above the local dynamical tropopause, corresponding to the extratropical tropopause transition layer (ExTL) as identified by CO. The LMS beyond this layer shows a relatively well defined separation as marked by an aprupt transition to longer $t_{\mathrm{TST}}$ indicating less frequent mixing and a smaller fraction of tropospheric air. Thus the LMS constitutes a region of two well defined regimes of tropospheric influence. These can be characterized mainly by different transport times from the troposphere and different fractions of tropospheric air.

Carbon monoxide (CO) mirrors this structure of $t_{\mathrm{TST}}$ due to it's finite lifetime on the order of three months. Water vapour isopleths, on the other hand, do not uniquely indicate TST and are independent of $t_{\mathrm{TST}}$, but are determined by the Lagrangian Cold Point (LCP) of air parcels. Most of the backward trajectories from the LMS experienced their LCP in the tropics and sub-tropics, and TST often occurs 20 days after trajectories have encountered their LCP. Therefore, ExTL properties deduced from $\mathrm{CO}$ and $\mathrm{H}_{2} \mathrm{O}$ provide totally different informations on transport and particular TST for the LMS.
\end{abstract}

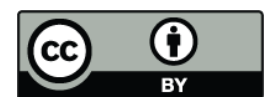

Correspondence to: P. Hoor (hoor@uni-mainz.de)

\section{Introduction}

The lowermost stratosphere (LMS) gained increasing attention in recent years due to its sensitivity to perturbations of ozone and its feedback on climate (e.g. Lacis et al., 1990; Forster and Shine, 1999). Bounded by the extratropical tropopause and the $\Theta=380 \mathrm{~K}$ surface it is the region where isentropes cross the tropopause (Holton et al., 1995). Therefore isentropic transport from the troposphere to the stratosphere occurs preferably in the region of the subtropical and polar jet (e.g. Lelieveld et al., 1997). The breaking of planetary waves along isentropic surfaces induces horizontal shear. This leads to stirring and mixing (Appenzeller et al., 1996a; Wirth and Szabo, 2007) associated with structures which decay on the microscale involving radiative and turbulent processes (Wirth and Szabo, 2007). Also breaking gravity waves associated with the topography (Schilling et al., 1999) or convection (Wang, 2003) can lead to tracer injection into the stratosphere (Fischer et al., 2003). From a dynamical point of view irreversible exchange across the tropopause requires an increase of potential vorticity (PV) of the involved air parcels to become part of the stratosphere. Since PV is conserved under adiabatic conditions diabatic processes are required to allow an irreversible exchange of air in both directions such as radiation, latent heating or clear air turbulence (e.g. Shapiro, 1980).

All these processes involve a broad range of temporal and spatial scales, thus the effect of cross tropopause transport on the distribution of photochemical tracers depends critically on properties of the tracer, particularly its lifetime and source and sink characteristics.

Trajectory experiments, that have investigated cross tropopause transport mostly focussed on distinct processes and regions (e.g. Bourqui, 2006; Konopka et al., 2007, 2009). A Lagrangian climatology by James et al. (2003) showed that

Published by Copernicus Publications on behalf of the European Geosciences Union. 

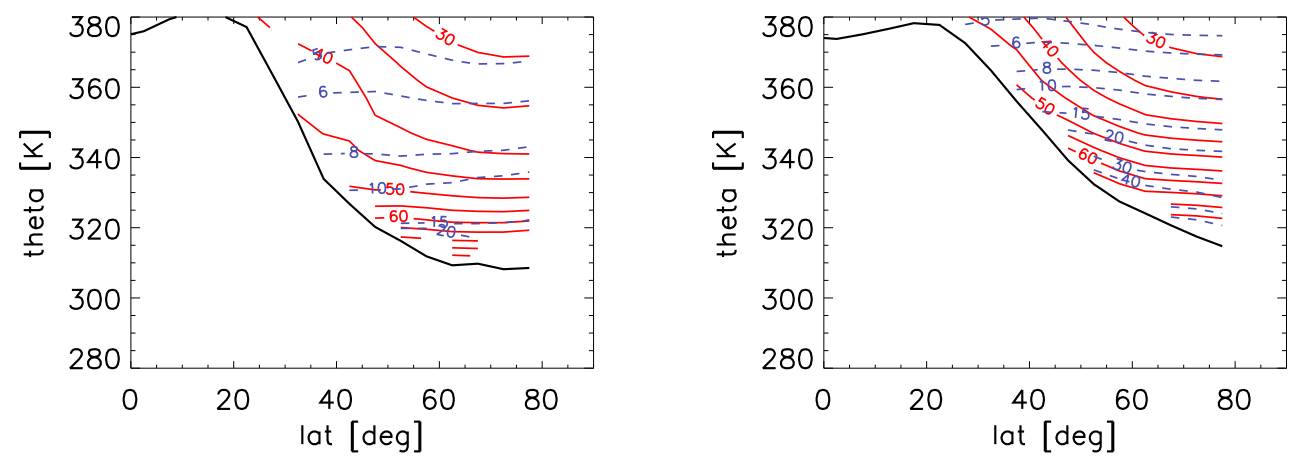

Fig. 1. Zonal mean distribution of $\mathrm{H}_{2} \mathrm{O}$ (blue dashed lines, in ppmv) and $\mathrm{CO}$ (red solid lines, in ppbv) on isentropes for northern winter (November, December, January, NDJ) (left) and summer (May, June, July, MJJ), respectively, as observed from the ACE-FTS instrument, black line denotes the tropopause. Only stratospheric observations with $\mathrm{O}_{3}>200 \mathrm{ppbv}$ were used. Note that CO isopleths are tilted against the quasi-isentropic water vapour isopleths.

the distribution of trace gases in the LMS is a function of time since tropopause crossing. Sprenger and Wernli (2003) identified preferred regions for exchange in the extratropics and a pronounced seasonality, in particular of the potential temperature where transport from the troposphere to the stratosphere occurs. Especially the seasonality of the strength of the PV-gradient at the subtropical jet has been identified to play a crucial role for the trace gas budget of the extratropical lowermost stratosphere with a much weaker jet and higher permeability allowing more exchange during summer than in winter (Haynes and Shuckburgh, 2000). A recent study by Berthet et al. (2007) based on Lagrangian trajectories found a strong contribution for air from the tropical troposphere in the extratropical LMS peaking in summer consistent with earlier findings based on tracer measurements (Hoor et al., 2005; Hegglin et al., 2006). They further concluded that the probability of an air parcel to enter the LMS shows a strong decline which is collocated with the dynamical tropopause over a broad range of mid latitudes. Thus the tropopause indicates a change of probability for an air parcel to enter the stratosphere.

To determine an upper boundary of the tropospheric influence in the LMS from photochemical tracers different species and methods have been used. Of particular interest are tracers with a well defined stratospheric background like $\mathrm{H}_{2} \mathrm{O}$ or $\mathrm{CO}$. Tracer mixing ratios exceeding these stratospheric background values are an indication for tropospheric influence. Dessler et al. (1995) and Pan et al. (2000) concluded from airborne profiles of $\mathrm{H}_{2} \mathrm{O}$ that irreversible transport across the extratropical tropopause and subsequent mixing has taken place. Fischer et al. (2000) introduced scatterplots of $\mathrm{CO}$ and ozone to identify transport from the troposphere and subsequent mixing as indicated by a region of intermediate $\mathrm{CO}$ mixing ratios between stratospheric and tropospheric values. Using airborne trace gas measurements in northern Europe and mid latitudes over continental North America Hoor et al. (2002) determined a layer depth with a weak seasonality using potential temperature relative to the $2 \mathrm{PVU}$ dynamical tropopause. Based on airborne measurements over Europe between $35^{\circ} \mathrm{N}$ and $75^{\circ} \mathrm{N}$ Hoor et al. (2004) concluded that the mixing region around the tropopause follows the local tropopause rather than isentropes. Pan et al. (2004) refined the correlation method by using probability density functions (PDF's) of the mixing region to determine the thickness of the layer and inferred a depth of $2-3 \mathrm{~km}$ for the chemical transition layer in the extratropics corresponding to $25-30 \mathrm{~K}$ in potential temperature units (Hoor et al., 2004). On the basis of $\mathrm{H}_{2} \mathrm{O}$ measurements obtained during SPURT Krebsbach et al. (2006) found a layer top exceeding the values from Hoor et al. (2004). This discrepancy is also evident in the study of Hegglin et al. (2009) who found different upper boundaries for the transition region based on the analysis of $\mathrm{CO}$ and $\mathrm{H}_{2} \mathrm{O}$ observations from the Atmospheric Chemistry Experiment Fourier Transform Spectrometer (ACE-FTS) onboard the Canadian SCISAT-1 satellite. They interpreted the discrepancy as a result of the different lifetimes of the two tracers.

The observed stratospheric distributions of $\mathrm{CO}$ and $\mathrm{H}_{2} \mathrm{O}$ from the ACE-FTS are shown in Fig. 1 for winter and summer, respectively. We selected an ozone threshold of $\mathrm{O}_{3}>200 \mathrm{ppbv}$ as criterion for stratospheric data since $\mathrm{PV}=2 \mathrm{PVU}$ was not available for the individual ACE-FTS profiles. The isopleths of both tracers are tilted against isentropes, but also show seasonally varying relationships against each other. The $\mathrm{CO}$ maximum in the subtropics at latitudes $<40^{\circ} \mathrm{N}$ is shifted to higher latitudes during summer thereby exhibiting higher $\mathrm{H}_{2} \mathrm{O}$ values for a given $\mathrm{CO}$ isopleth. Higher water vapour mixing ratios (in parts per million by volume, ppmv) for given $\mathrm{CO}$ values (in parts per billion by volume, ppbv) can also be observed further north as indicated by the location of e.g. the $\mathrm{H}_{2} \mathrm{O}=30$ ppmv isopleth relative to the $\mathrm{CO}=60 \mathrm{ppbv}$ contour. In particular north of $40^{\circ} \mathrm{N}$ and $\Theta<340 \mathrm{~K}$ the relation between $\mathrm{H}_{2} \mathrm{O}$ and $\mathrm{CO}$ shows large seasonal variations with much drier air at given 
$\mathrm{CO}$ isopleths during winter. These findings can only partly be attributed to seasonal variations of the dynamical conditions in the LMS which change the relation between $\mathrm{CO}$ and $\mathrm{H}_{2} \mathrm{O}$. However, also microphysical and chemical processes determine the distribution of both tracers thereby interacting with the underlying dynamics.

In this study we use a Lagrangian approach to investigate in particular the relation between transport time and temperature, which both affect the abundance of $\mathrm{CO}$ and $\mathrm{H}_{2} \mathrm{O}$ in the stratosphere. Previous studies have shown the potential of merging trace gas measurements with Lagrangian analyses (e.g. Hegglin et al., 2004; Pan and Browell, 2006; James and Legras, 2009), but most of these where restricted to case studies. For our analysis we used a statistical data set of 90 day backward trajectories which were initialized in the LMS at two arbitrary days in winter and summer, respectively. We focus in our analysis on transport time since last tropopause crossing for troposphere-to-stratosphere-transport (TST) and the minimum temperature along the trajectory since these two quantities strongly determine the distribution of particular water vapour and a tracer with finite lifetime like CO.

In this paper we want to address the following questions:

1. What are characteristic transport time scales for TSTtrajectories within the extratropical lowermost stratosphere?

2. What is the relation between dehydration and TST for air in the lowermost stratosphere?

3. What controls the abundance of water vapour and $\mathrm{CO}$ in the extratropical lowermost stratosphere?

4. What are the consequences for the definition of the extratropical transition layer (ExTL) on the basis of these two tracers?

Section 2 briefly introduces the trajectory analysis. The results are presented in Sect. 3, which are discussed in Sect. 4.

\section{Trajectory setup}

To investigate the relationship of $\mathrm{CO}$ and $\mathrm{H}_{2} \mathrm{O}$ to transport properties we calculated 90 day backward trajectories initialized on 1 February 2008 and 1 August 2008 for northern winter and summer, respectively, using the LAGRANTO tool as described in Wernli and Davies (1997). The trajectories were initialized in the lowermost stratosphere of the Northern Hemisphere ( $\mathrm{PV}>2 \mathrm{PVU})$ in steps of $5 \mathrm{~K}$ on isentropic levels up to $\Theta=380 \mathrm{~K}$. A horizontal grid spacing of $80 \times 80 \mathrm{~km}$ was used which led to typically 40000 trajectories on each isentropic surface depending on the area of the lowermost stratosphere on each level. The trajectories were driven using horizontal and vertical winds from high resolution operational analyses (T799L91) provided by the European Centre for Medium-Range Weather Forecasts (ECMWF) interpolated onto a regular grid with $0.5^{\circ}$ horizontal resolution.
For a comparison of trajectories with $\mathrm{CO}$ and $\mathrm{H}_{2} \mathrm{O}$ and the investigation of those transport properties, which are related to the abundance of both tracers in the stratosphere we determined trajectories which indicate troposphere-tostratosphere-transport (TST). We further analysed the trajectories for their Lagrangian cold point (LCP) which is defined as the location where the coldest temperature appears along the 90-day backward trajectory. We further calculated the $\mathrm{H}_{2} \mathrm{O}$ saturation mixing ratio over ice for the temperature at the LCP similar to Fueglistaler et al. (2004) using the formula of Marti and Mauersberger (1993).

In the following we will use the following abbreviations and definitions:

The temperature and saturation mixing ratio at the LCP are denoted as $T_{\mathrm{LCP}}$ and $\mathrm{H}_{2} \mathrm{O}_{\mathrm{LCP}}$, sat, respectively.

The elapsed time since LCP-encounter will be indicated by $t_{\mathrm{LCP}}$ and the time since last TST $t_{\mathrm{TST}}$, which is equivalent to a stratospheric residence time of the respective air parcel trajectory.

Trajectories were regarded as TST-trajectories when their PV decreased to levels below 2 PVU and $\Theta<380 \mathrm{~K}$ backward in time. Additionally, we applied a residence time criterion to the trajectory similar to Wernli and Bourqui (2002) requiring that the air parcel remained for at least $24 \mathrm{~h}$ in the troposphere before the TST-event. We then deduced TST-properties such as TST-latitude, time since crossing and TST-temperature from the first stratospheric point after tropopause crossing with $\mathrm{PV}>2 \mathrm{PVU}$. A sensitivity study using the last tropospheric point as crossing location did not reveal significant differences to the aforementioned setup.

As discussed in Fueglistaler et al. (2005) it is clear that trajectories may not cover all processes in detail which lead to a modification of water vapour mixing ratios along trajectories particularly associated with microphysical processes and clouds. However, as shown by Fueglistaler et al. (2005) and Fueglistaler and Haynes (2005) trajectories on the basis of the synoptic and large scale circulation as resolved by the ERA-40 wind fields are able to explain the observations of $\mathrm{H}_{2} \mathrm{O}$ from HALOE and SAGE as well as radio sondes within $0.2 \mathrm{ppmv}$.

Differing from the calculations of Fueglistaler et al. (2005) and Fueglistaler and Haynes (2005) our calculations are based on operational ECMWF data with an unprecedented resolution of T799L91 (Simmons et al., 2006; Uppala et al., 2008). The higher resolution may limit potential artefacts caused by excessive vertical dispersion when using 3-D wind fields instead of heating rates for the calculation of trajectories as shown by Tegtmeier et al. (2008) and Krüger et al. (2008). However, these studies were based on ERA-40 data and operational ECMWF data with differing resolutions. As shown in Liu et al. (2010) by systematically comparing kinematic and diabatic trajectories using ERA-40 and ERA interim data, respectively, the use of kinematic trajectories in ERA interim results in only a relative small dispersion in $\Theta$ for the kinematic trajectories particularly in the LMS. A 

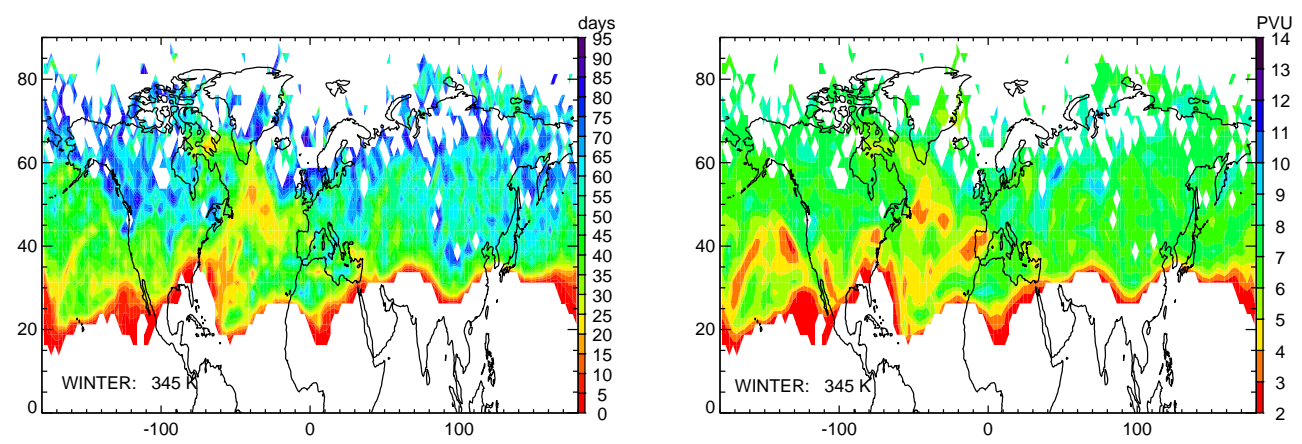

Fig. 2. Distribution of $t_{\mathrm{TST}}$ on the $\Theta=345 \mathrm{~K}$ isentrope for trajectories initialized in the LMS at 00:00 UTC, on 1 February 2008 (left), and PV distribution at the same time (right). White areas at mid and high latitudes denote regions where no crossing trajectories are found. The tropopause (2PVU) corresponds to $t_{\mathrm{TST}}=0$ at latitudes $<40^{\circ} \mathrm{N}$. White areas south of $40^{\circ} \mathrm{N}$ are tropospheric where no trajectories were initialized. The gradient from red to blue indicates increasing $t_{\mathrm{TST}}$ (left) as well as increasing PV (right) with distance from the tropopause.

study by Ploeger et al. (2010) shows that operational data in the tropics tend to give too rapid vertical upwelling in the tropics, but a similar probability and budget for quasihorizontal inmixing into the TTL from the LMS, which gives some confidence that the quasi-horizontal exchange with the extratropics is reasonable also for operational data. Despite the tendency of too strong vertical upwelling in the tropics the 4D-Var (four-dimensional variational) assimilated operational ECMWF and ERA interim wind fields improve significantly the vertical and horizontal transport in the stratosphere compared to the 3D-Var assimilated ERA-40 data. This results in a much more realistic mean age of air distribution in the lower stratosphere (Meijer et al., 2004; Monge-Sanz et al., 2007). However, a systematic investigation of the T799L91 operational data with focus on the extratropics is not available and uncertainties remain. A potentially larger vertical dispersion of trajectories will have only a minor effect on the quantities and the mean distribution of the parameters on which we focus as discussed in Sect. 4.

\section{Results}

We analyze the trajectories from an experimentalist's view who is interested in the composition of the lowermost stratosphere at a given time $(t=0)$. The abundance of a tropospheric tracer in the LMS at a given time $t=0$ can be regarded as the result of mixing of individual air parcels with different transport histories, such as different $t_{\mathrm{TST}}$, photochemical processes or states of mixing. Trajectory calculations do not account for mixing. However, we will analyze the trajectories by binning trajectory properties of our statistical data set, which in turn leads to a mixture of individual trajectories in each bin. We remapped the crossing parameters of the TST-trajectories to their starting grid at time $t=0$ (i.e. the time of initialization). Thus, we obtain spatial maps of the history of TST parameters of the last 90 days at the time of initialization $(t=0)$, which is equivalent to a
Lagrangian forward projection of air parcel properties as described in Liniger and Davies (2003). In the following we will focus on the spatial distribution of transit times of the trajectories since they crossed the tropopause (2 PVU) as described in the previous section.

\subsection{TST trajectories and transit times}

Figure 2 (left) shows the spatial distribution of $t_{\mathrm{TST}}$ on the $\Theta=345 \mathrm{~K}$ isentrope for the winter case (1 February 2008). White areas south of $40^{\circ} \mathrm{N}$ denote tropospheric air since trajectories were initialized only in the LMS where PV $>2$ PVU. Thus the $2 \mathrm{PVU}$ isoline is identical to the transition from white to red coloured regions between $20-30^{\circ} \mathrm{N}$. A gradient of $t_{\mathrm{TST}}$ is evident, which indicates in general increasing transit times with distance from the $2 \mathrm{PVU}$ isoline. Particularly the region with transit times $<20$ days tends to form a narrow band which follows the dynamical tropopause indicating an area of recent and frequent TST. With larger distances the distribution of crossing times becomes more diverse showing some filamentary structures of younger air over the northern Atlantic as well as regions in the far north where the air had no tropospheric contact within the last 90 days.

The similarity of the PV-distribution for the same day at $t=0$ (Fig. 2, right) particularly for $\mathrm{PV}<5 \mathrm{PVU}$ with the patterns of frequent and short term exchange is striking. Even the filamentary structures of the PV are evident in the distribution of short transit times. For longer transit times the agreement with PV collapses showing no clear correlation between PV and transit time. In these regions the PV is modified by dynamical processes within the stratosphere such as differential advection leading to stirring and mixing as well as radiative processes acting on longer timescales (Shepherd, 2007). Therefore the clear relationship between TST-transit times and PV no longer holds. However as indicated by the time distribution of the TST trajectories in Fig. 2 (left) tropospheric air is not randomly distributed in the lowermost stratosphere and there's still a latitudinal gradient evident 

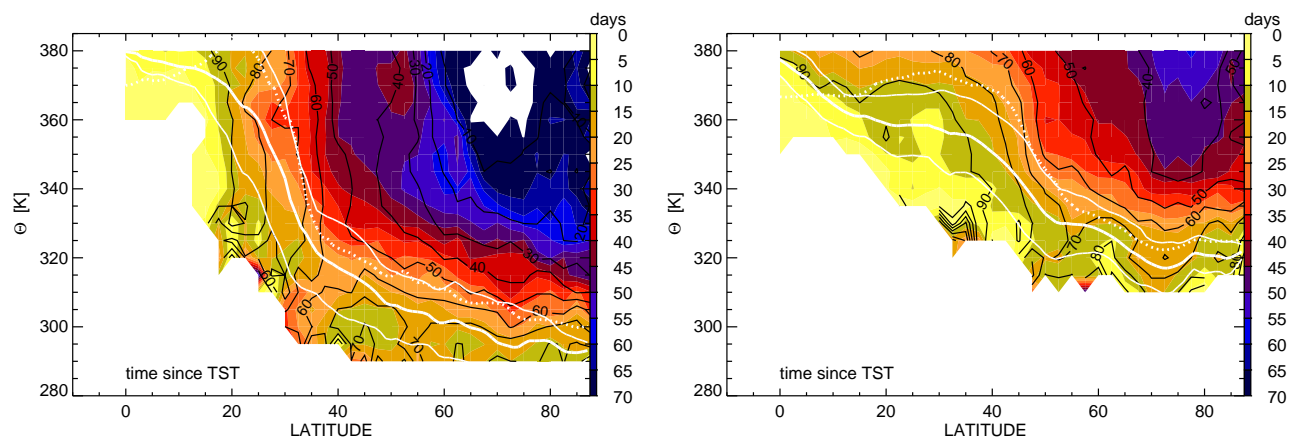

Fig. 3. Zonal mean distribution of $t_{\mathrm{TST}}$ on 1 February (left) and 1 August 2008 (right), respectively, when trajectories were initialised. The gradient from yellow to blue indicates increasing $t_{\mathrm{TST}}$ with distance to the tropopause $\left(t_{\mathrm{TST}}=0\right)$. Black contours indicate the fraction of TST trajectories in percent. The dotted white line indicates the zonal mean thermal tropopause, solid white lines indicate the location of the 3.5 PVU isosurface with standard deviation for the respective days.

indicating an increasing "age" of the trajectories away from the tropopause.

This behaviour is also evident in the global zonal mean distributions of $t_{\mathrm{TST}}$ (Fig. 3) for northern winter and summer. The seasonal comparison confirms the finding of a tropopause following layer for short transit times as discussed above (Fig. 2, left). Note that the strong horizontal gradient of transit times which is evident above $\Theta=320 \mathrm{~K}$ changes to a vertical gradient at lower isentropes for latitudes $>40^{\circ} \mathrm{N}$. The mean position of the 2-PVU isosurface is located below the thermal tropopause, but both are within a region characterized by $t_{\mathrm{TST}}<30$ days. Some seasonal differences are also evident in Fig. 3. The tropopause following structure can be identified in both seasons. However, during summer the LMS is characterized by shorter $t_{\mathrm{TST}}$ even in polar regions, which can be attributed to a combination of different effects. In summer the isentropic PV-gradient is at minimum and the effective diffusivity shows a maximum at the subtropical jet region (Haynes and Shuckburgh, 2000) facilitating TST (Berthet et al., 2007) particularly at higher isentropes (Sprenger and Wernli, 2003). On the other hand, the stratospheric downwelling of the Brewer-Dobson circulation is strongest during winter (Appenzeller et al., 1996b) leading to a stronger diabatic descent of TST trajectories with time during winter, which reduces the probability for TST trajectories to stay in polar regions above $330 \mathrm{~K}$.

\subsection{Transit time and PV distribution}

The relationship between $t_{\mathrm{TST}}$ and PV at $t=0$ for each individual trajectory confirms these findings and reveals seasonal differences. Figure 4 shows the correlation of $t_{\mathrm{TST}}$ and PV at $t=0$ in the LMS, where the trajectories were initialized. During winter the transition from tropospheric PV to stratospheric background of approximately 8-9 PVU occurs within 10 days up to $\Theta<330 \mathrm{~K}$ indicating strong PVmodifications due to intense diabatic processes. These enable tropospheric air parcels to become irreversibly transferred into the LMS and a part of stratospheric background in that region within less than two weeks. At higher isentropes a shift to longer time scales is evident indicating longer time scales for the processes leading to a TST-event. A comparison to Fig. 3 shows that during winter the region below $\Theta=330 \mathrm{~K}$ is dominated by a quasi-isentropic structure of $t_{\mathrm{TST}}$. At higher isentropes the isolines for $t_{\mathrm{TST}}$ are steeply tilted towards isentropes in close vicinity to the tropopause. Figure 4 reveals a much more rapid transition during summer and more efficient diabatic processes which lead to shorter $t_{\mathrm{TST}}$. This is in line with a weaker PV-gradient at the subtropical jet and a higher potential temperature at the extratropical tropopause.

Importantly the correlation between $t_{\mathrm{TST}}$ and $\mathrm{PV}(t=0)$ collapses when TST-air parcels have reached their stratospheric background PV, which means that they are from a dynamical point of view a part of the stratospheric background. At far distances from the tropopause diabatic processes are decoupled from diabatic processes occurring at tropopause levels or below, such as gravity wave breaking, clear air turbulence at the jet, stirring and mixing associated with baroclinic waves or cloud condensation. These might all contribute to the rapid transition at lower isentropes, i.e. close to the tropopause. Within the stratosphere stirring and mixing driven by horizontal shear from synoptic and planetary wave breaking occurs which leads to mixing as well as radiative processes. However, since these processes are not related to the exchange process itself, the transit time is no longer correlated to the PV.

\subsection{Lagrangian Cold Points in the lowermost stratosphere}

The saturation mixing ratio of water vapour which enters the stratosphere across the tropopause is controlled by the temperature $T_{\mathrm{LCP}}$ of the TST-trajectories. LCP-temperatures for 1 February and 1 August are displayed in Fig. 5 and are projected to the initialization coordinates at $t=0$ (i.e. the "time 

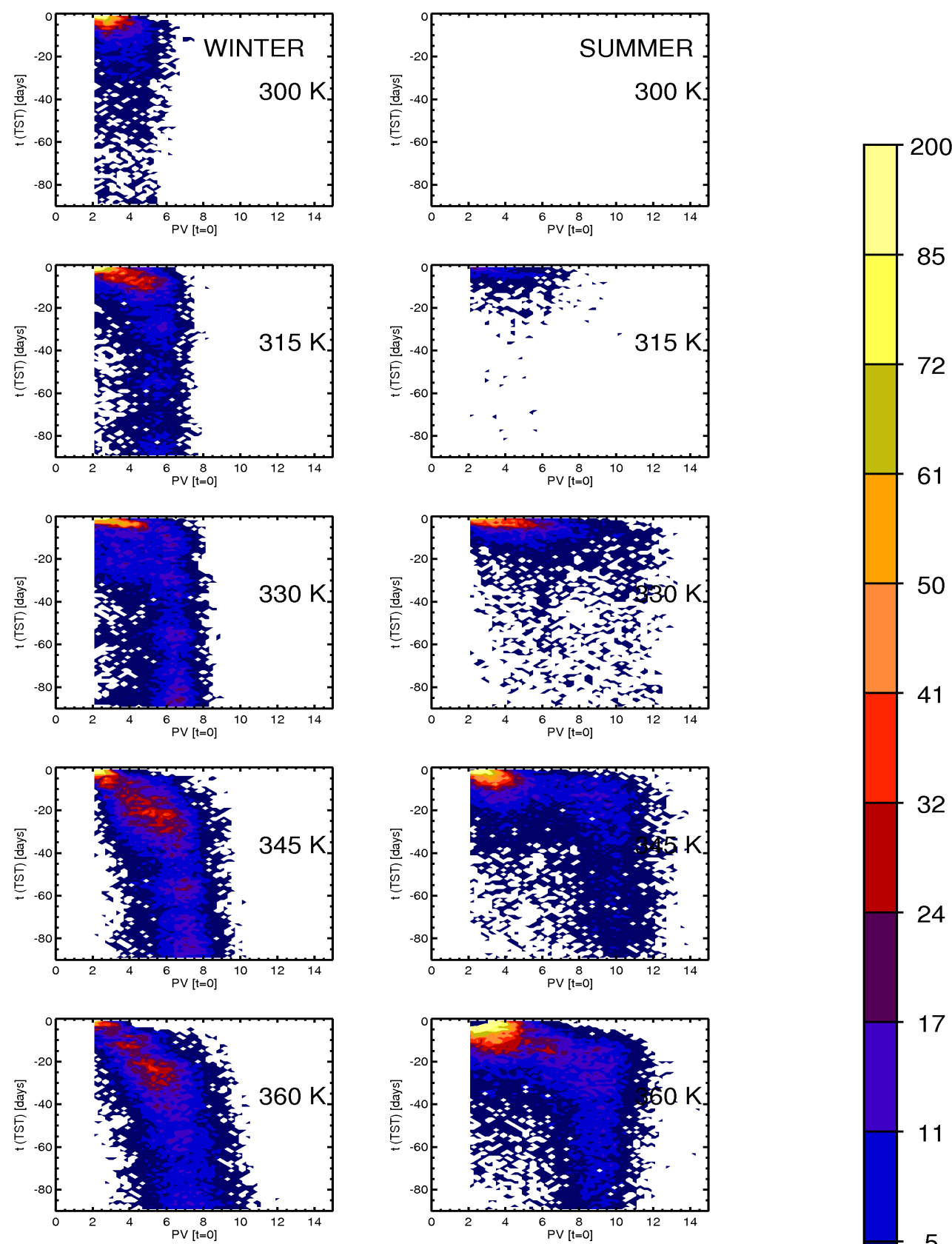

\section{0}
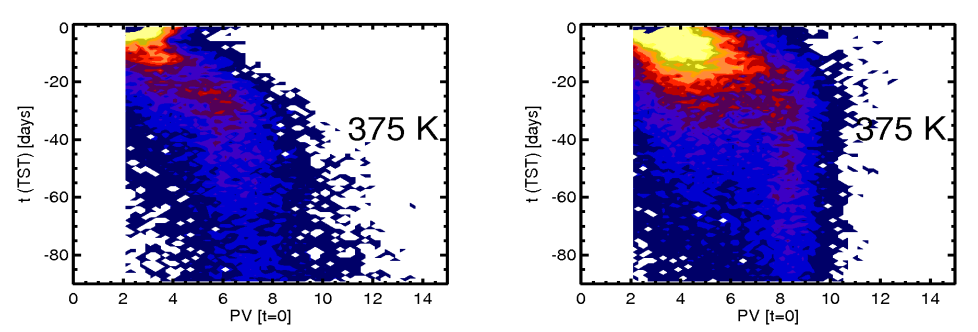

Fig. 4. Scatter plot of PV at time of trajectory initialization $(t=0)$ and time since last TST $\left(t_{\mathrm{TST}}\right)$ on different isentropes from $\Theta=300-375 \mathrm{~K}$ in steps of $15 \mathrm{~K}$ for winter(left) and summer(right), respectively. The colours show the number of data points binned in steps of $0.2 \mathrm{PVU}$ and one day with higher number densities in yellow to red. 

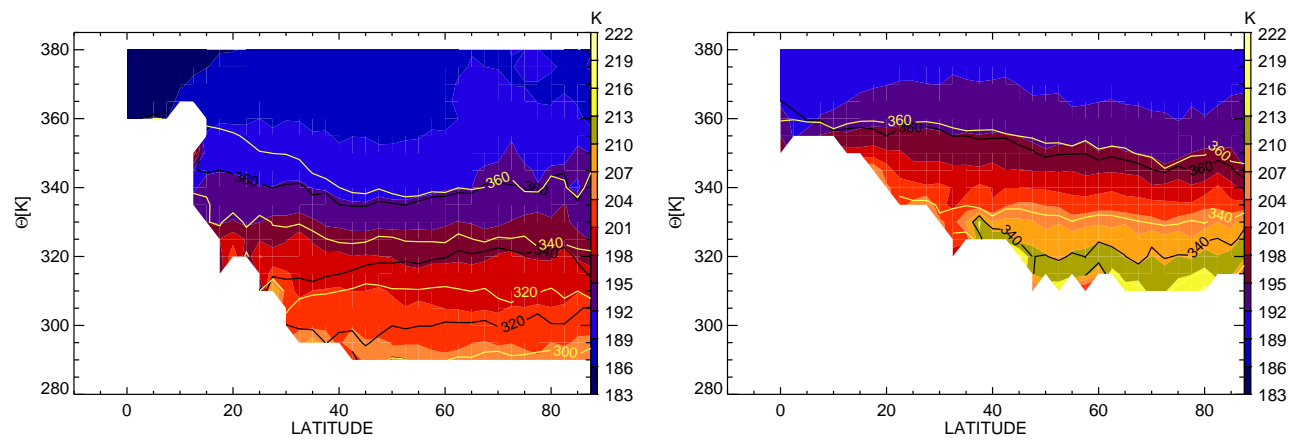

Fig. 5. As Fig. 3 but for the Lagrangian cold point temperature $T_{\mathrm{LCP}}$ of TST trajectories projected to $t=0$ for northern winter (left) and summer (right), warm colours denote higher temperatures. Solid contours show potential temperature $\Theta$ [K] during TST (yellow) and at LCP (black), both also projected to $t=0$.
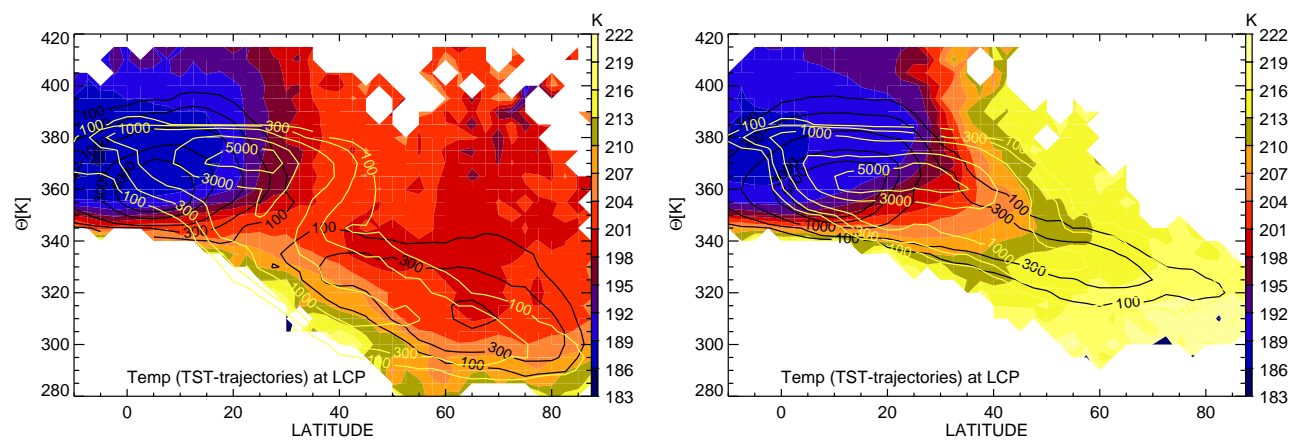

Fig. 6. Zonal mean cross section of $T_{\mathrm{LCP}}$ at the location of LCP of each TST trajectory for northern winter (left) and summer (right). Colours are as in Fig. 5, black contours denote the number of trajectories at their location of LCP, yellow contours indicate the number of trajectories at their individual TST location (both number contours from $2.5^{\circ} \times 5 \mathrm{~K}$-bins).

of measurement"). During winter mean $T_{\mathrm{LCP}}$ at the extratropical tropopause around $\Theta=290 \mathrm{~K}$ are around $-66^{\circ} \mathrm{C}$ decreasing to $-80{ }^{\circ} \mathrm{C}$ at $\Theta=340 \mathrm{~K}$. The coldest $T_{\mathrm{LCP}}$ can be found in the TTL region above $\Theta=360 \mathrm{~K}$ where they fall below $-87^{\circ} \mathrm{C}$. During summer the tropopause in the extratropics can be found at higher isentropes around $\Theta=310 \mathrm{~K}$ and exhibit higher $T_{\mathrm{LCP}}$ around $-57^{\circ} \mathrm{C}$. The LMS in general is warmer and the $T_{\mathrm{LCP}}=-81^{\circ} \mathrm{C}$-isotherm is shifted towards higher $\Theta=365 \mathrm{~K}$. Most importantly and as evident from Fig. 5 the lowermost stratosphere shows an almost horizontal distribution of $T_{\mathrm{LCP}}$. Moreover, although Fig. 5 (left) is generated using the same subset of data as in Fig. 3 it shows a totally different structure. The quasi-isentropic distribution of $T_{\mathrm{LCP}}$ in the lowermost stratosphere indicates, that irrespective of latitude (and hence the elapsed stratospheric trajectory residence time $t_{\mathrm{TST}}$ ) air parcels on the same isentrope experience very similar $T_{\mathrm{LCP}} \mathrm{s}$. We will discuss the consequences for $\mathrm{H}_{2} \mathrm{O}_{L C P}$, sat in the next section.

To investigate the effect of diabatic downwelling related to the Brewer-Dobson circulation within the lowermost stratosphere Fig. 5 also shows the contours of potential temperature $\Theta_{\mathrm{LCP}}$ and $\Theta_{\mathrm{TST}}$ where each trajectory encountered its LCP (black) and TST (yellow), respectively, both pro- jected to $t=0$. At mid and high latitudes during winter $\Theta_{\mathrm{LCP}}=360 \mathrm{~K}$ is found at $\Theta=340 \mathrm{~K}$ at $t=0$, which indicates a diabatic descent from the time of LCP to $t=0$. A displacement of $\Theta_{\mathrm{LCP}}$ and $\Theta_{\mathrm{TST}}$ to lower isentropes is evident above $\Theta=330 \mathrm{~K}$ indicating a diabatic downward component, which however almost disappears during summer in accordance with the background circulation of air. Note further, that $\Theta_{\mathrm{LCP}}$ and $\Theta_{\text {TST }}$ are different which indicates that TST and LCP occur not at the same location. Consider an air mass which is located at $t=0$ at $\Theta=310 \mathrm{~K}$ at $60^{\circ} \mathrm{N}$ (Fig. 5, left). Its $\Theta_{\mathrm{TST}}$ is $320 \mathrm{~K}$ (yellow contour), but its $\Theta_{\mathrm{LCP}}$ is between 320 and $340 \mathrm{~K}$ (black lines). Since $\Theta_{\mathrm{LCP}}$ is higher than $\Theta_{\mathrm{TST}}$ and the stratosphere is dominated by diabatic descent, this is an indication, that the air parcels become dehydrated and subsequently descend before they undergo a TST. Therefore the assignment of $\mathrm{H}_{2} \mathrm{O}_{L C P}$, sat to TST and transport into the lowermost stratosphere is arbitrary and not unique, as will be discussed later.

\subsection{Relation between LCP and TST}

Since $\Theta_{\text {LCP }}$ and $\Theta_{\text {TST }}$ differ significantly we investigate the relation between TST and LCP in more detail. Figure 6 

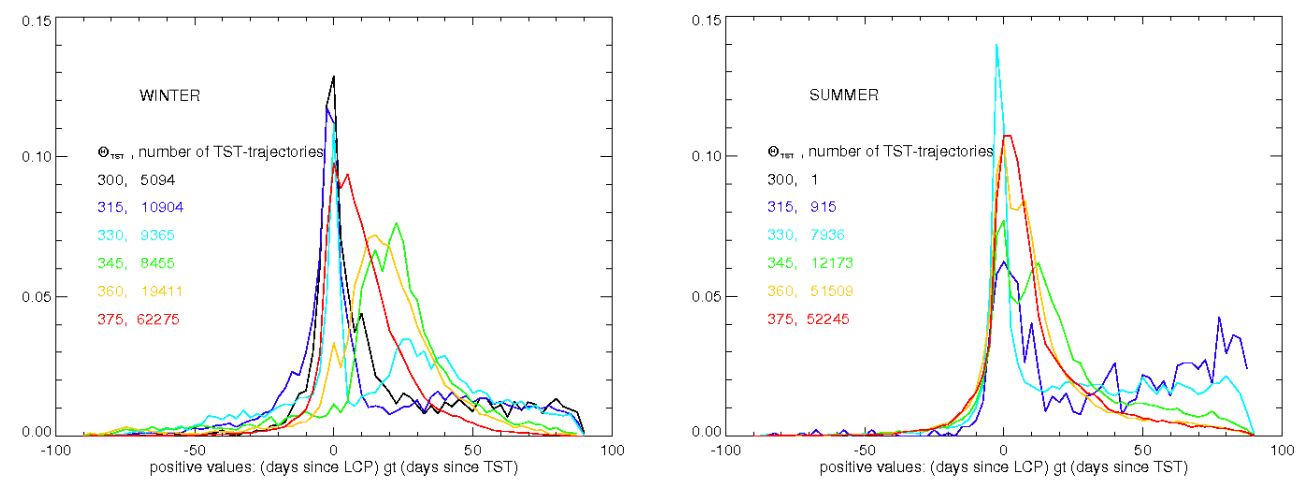

Fig. 7. Normalized probability density functions for the time difference of LCP and TST for TST-trajectories undergoing their TST on different isentropes from $300-375 \mathrm{~K}$ in steps of $15 \mathrm{~K}$ (colour code) for northern winter (left) and summer (right). Going forward in time positive values indicate that the air parcels encountered their LCP before they crossed the tropopause.

shows the temperature distribution $T_{\mathrm{LCP}}$ at the location where each individual trajectory encountered its LCP. Lowest $T_{\mathrm{LCP}}$ are apparent in the TTL region and higher $T_{\mathrm{LCP}}$ throughout the extratropical LMS, the latter tied to a strong seasonal cycle. A comparison with Fig. 5 reveals significant differences between $T_{\mathrm{LCP}}$ projected to $t=0$ and $T_{\mathrm{LCP}}$ at the LCP-location (Fig. 6). The latitudinal gradient of $T_{\mathrm{LCP}}$ at the location and time of the LCP changes to a more isentropic structure, when projected to $t=0$, which can be attributed to a strong isentropic component of stratospheric transport. Furthermore, in the extratropics north of $40^{\circ} \mathrm{N}$ mean $T_{\mathrm{LCP}}$ at $t=0$ (Fig. 5) is colder everywhere in the LMS than at the location of LCP. Since both figures show the same subset of trajectories, this indicates that a redistribution of $T_{\mathrm{LCP}}$ occurred over time reducing mean $T_{\mathrm{LCP}}$ in the extratropical LMS at $t=0$. Notably a large fraction of air parcels is advected from regions with low $T_{\mathrm{LCP}}$ to the extratropics where $T_{\mathrm{LCP}}$ is higher during the time of LCP (Fig. 6) than at $t=0$ (Fig. 5). Particularly during summer transport of air with low LCP-temperatures to the extratropics is needed to explain the LCP-temperature distribution at $t=0$.

The black contours show the number density for LCP and indicate the preferred region for dehydration. During winter there's a clear separation at $\Theta=340 \mathrm{~K}$ : above, the LCP is encountered in the TTL-region south of the region of TST which shows a maximum at $25^{\circ} \mathrm{N}$. At lower altitudes a reverse pattern is evident indicating that dehydration occurs at higher latitudes than the TST-transition (yellow contours). In summer, the locations of LCP and TST have a greater overlap, implying that dehydration and TST are closer related to each other. However, TST particularly above $\Theta=340 \mathrm{~K}$ appears at higher latitudes whereas the LCP temperature minimum is encountered in the TTL region.

Since the locations of TST and LCP are different (Fig. 6) we also investigated the time shift between both. We therefore compared the time difference between the time of TST $\left(t_{\mathrm{TST}}\right)$ and the time of LCP $t_{\mathrm{LCP}}$. If dehydration is occurring close to TST this difference should be close to zero, whereas large time differences indicate a temporal separation between the two events. As evident from Fig. 7 the distribution of this difference is shifted to positive values particular during winter at $\Theta$-levels between $330-360 \mathrm{~K}$, somewhat less pronounced during summer. In winter, a significant fraction of air masses show temporal separations of more than 30 days between TST and LCP. The positive shift indicates that these trajectories are dehydrated in the troposphere before they undergo TST. During summer the separation is not as broad, but still on the order of 10 days for a large fraction of air parcels.

Due to the large temporal separation and the different locations of TST and LCP (Fig. 6) for a large fraction of the trajectories no clear relationship between the two can be assumed. Therefore the corresponding $\mathrm{H}_{2} \mathrm{O}$ saturation mixing ratios are not necessarily indicative for the conditions at the TST location. We will discuss this result in more detail in the next section.

\section{Discussion}

\subsection{Water vapour and TST in the extratropics}

As shown above a significant fraction of TST trajectories originate in the tropical troposphere and exhibit very low $T_{\mathrm{LCP}}$ at isentropes down to $\Theta=350 \mathrm{~K}$. These trajectories also reduce the mean $T_{\mathrm{LCP}}$ in the extratropical LMS. Since the maximum amount of water vapour in an air parcel is directly linked to $T_{L C P}$ via $\mathrm{H}_{2} \mathrm{O}_{\mathrm{LCP} \text {, sat }}$, trajectories with very low $T_{L C P}$ lead to a dilution of $\mathrm{H}_{2} \mathrm{O}$ in the extratropics rather than an enhancement. The distribution of $\mathrm{H}_{2} \mathrm{O}_{L C P}$, sat for all TST-trajectories projected to $t=0$ in Fig. 8 thus resembles the structure of $T_{\mathrm{LCP}}$ and shows the water vapour amount, which can be transported into the lowermost stratosphere. A closer inspection of Fig. 8 reveals that during winter the layer of $\mathrm{H}_{2} \mathrm{O}_{L C P}$, sat $=5-7$ ppmv coincides roughly with the $\Theta=330-340 \mathrm{~K}$-isentrope whereas in summer the 

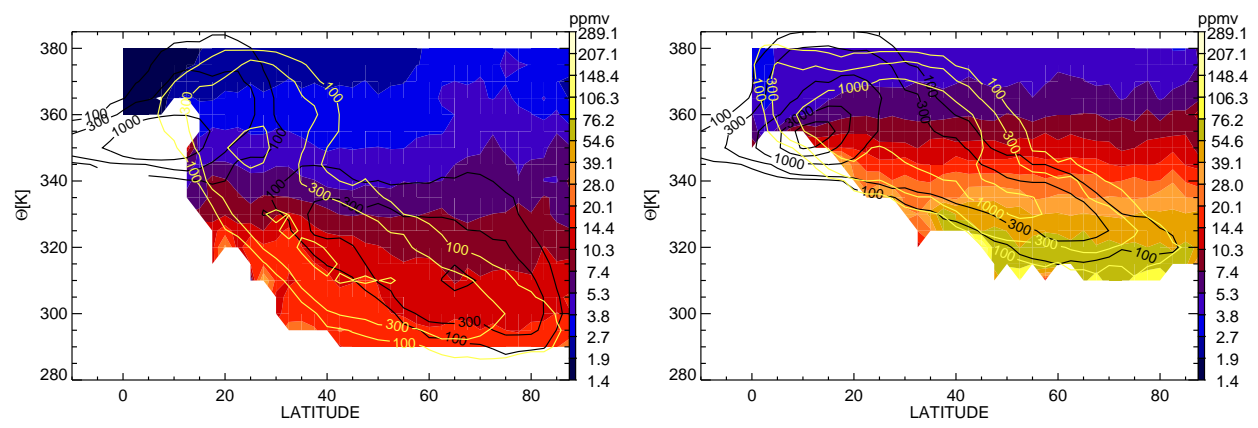

Fig. 8. As Fig. 3 but for the saturation mixing ratio $\mathrm{H}_{2} \mathrm{O}_{\mathrm{LCP}}$, sat of all TST-trajectories projected to $t=0$ for northern winter (left) and summer (right). Colours from yellow to blue indicate the transition from high to low water vapour mixing ratios. For those trajectories with LCP-saturation $\mathrm{H}_{2} \mathrm{O}_{\text {LCP, sat }}>5$ ppmv black contours indicate the location of LCP, yellow contours show the location of TST (number in $2.5^{\circ} \times 5$ K-bins).

same isopleths appear at $\Theta=360-370 \mathrm{~K}$ in accordance with a higher $T_{\mathrm{LCP}}$ in Fig. 5. The seasonality of $\mathrm{H}_{2} \mathrm{O}_{\mathrm{LCP}}$, sat indicates, that the whole extratropical lowermost stratosphere can potentially receive more water vapour during summer than in winter. This is in accordance with satellite based climatologies (e.g. Randel et al., 2001), which show a similar behaviour with significantly higher $\mathrm{H}_{2} \mathrm{O}$ during summer compared to winter (see Fig. 1).

We also investigated the tropospheric origin of a subset of TST-trajectories with $\mathrm{H}_{2} \mathrm{O}_{\mathrm{LCP} \text {,sat }}>5$ ppmv which potentially enhance stratospheric background water vapour. The contours in Fig. 8 show the locations of LCP and TST for these trajectories (a subset of contours in Fig. 6). They show that during both winter and summer a substantial amount of air parcels with $\mathrm{H}_{2} \mathrm{O}_{\mathrm{LCP}}$, sat $>5 \mathrm{ppmv}$ originates in the lower part of the TTL region between 350 and $360 \mathrm{~K}$. During winter a secondary maximum for the location of dehydration is evident around $\Theta=310 \mathrm{~K}$ at $65^{\circ} \mathrm{N}$ where a substantial amount of air becomes dehydrated north of the preferred TST-locations at these isentropes. This bimodal pattern for the distribution of dehydration disappears in summer.

Although a large number of TST trajectories with $\mathrm{H}_{2} \mathrm{O}_{\text {LCP,sat }}>5$ ppmv enter the stratosphere above $\Theta=340 \mathrm{~K}$ during winter and $370 \mathrm{~K}$ during summer, respectively, Fig. 8 shows that $\mathrm{H}_{2} \mathrm{O}_{\text {LCP, sat }}$ at $t=0$ is lower than $5 \mathrm{ppmv}$ at and above these isentropes particularly during winter. A contribution of TST-trajectories with $\mathrm{H}_{2} \mathrm{O}_{\text {LCP,sat }}<5$ ppmv is therefore needed to explain the low $\mathrm{H}_{2} \mathrm{O}_{L C P}$, sat values. Such trajectories carrying $\mathrm{H}_{2} \mathrm{O}_{L C P}$, sat $<5$ ppmv most likely originate from the upper part of the TTL above $350 \mathrm{~K}$, where the coldest $T_{\mathrm{LCP}}$ occur (Fig. 5). In fact, the largest fraction of TST-air parcels which contribute to the extratropical UTLS composition are dehydrated in the TTL region (Fig. 6, black contours). These trajectories dilute elevated $\mathrm{H}_{2} \mathrm{O}$ from TSTs at lower isentropes and higher LCP-temperatures as already concluded from the analysis of $T_{\mathrm{LCP}}$ in the previous section. During summer, the dilution effect is less pronounced since $T_{\mathrm{LCP}}$ is higher in the TTL.
It can therefore be concluded that water vapour in the extratropical LMS is decoupled from the time and the location of TST. Particularly the abundance of $\mathrm{H}_{2} \mathrm{O}$ in the extratropical LMS does not allow to differentiate between tropical and non-tropical origin since it is a mixture of moist extratropical tropospheric air with high $\mathrm{H}_{2} \mathrm{O}_{L C P}$,sat and air which has passed the TTL-region with very low $\mathrm{H}_{2} \mathrm{O}_{L C P}$,sat.

To assess the effect of mixing with stratospheric background air on the LMS tracer composition we performed a sensitivity study. We assigned a stratospheric $\mathrm{H}_{2} \mathrm{O}-$ background value of 5 ppmv to all non-TST trajectories, which stay in the stratosphere over the whole calculation period. All TST and non-TST trajectories are then binned into $5^{\circ}$ latitude by $5 \mathrm{~K}$ potential temperature boxes, yielding water vapour mixing ratios that approximate the mixed (and therefore final or observed) composition of the LMS. This approach is a coarse approximation of the true conditions, since we do not account for seasonal variations of the stratospheric $\mathrm{H}_{2} \mathrm{O}$ background. However, since we are interested in the structure rather than the absolute $\mathrm{H}_{2} \mathrm{O}$ values, the approach provides a sensitivity test for the effect of stratospheric background air on the structure of $\mathrm{H}_{2} \mathrm{O}$ isopleths. Figure 9 shows the resulting structure of $\mathrm{H}_{2} \mathrm{O}_{\mathrm{LCP}}$, sat when accounting for stratospheric air. Compared to Fig. 8 lower $\mathrm{H}_{2} \mathrm{O}_{\mathrm{LCP}}$, sat is evident throughout the lowermost stratosphere during summer and even more pronounced during winter. In addition slight modifications of the $\mathrm{H}_{2} \mathrm{O}_{L C P}$, sat isopleth structures can be found with a stronger shift to lower isentropes in winter. A weaker contribution of stratospheric background in summer is in accordance with a weaker downwelling from the stratosphere above $\Theta=380 \mathrm{~K}$ (Appenzeller et al., 1996b; Sprenger and Wernli, 2003), which dilutes $\mathrm{H}_{2} \mathrm{O}_{L C P}$, sat less in this season. Rapid transport on shorter timescales $\left(t_{\mathrm{TST}}\right.$, Fig. 3$)$ leads to a more efficient quasi-isentropic distribution of $\mathrm{H}_{2} \mathrm{O}_{L C P}$, sat during summer compared to winter which is reflected in the weaker change of the $\mathrm{H}_{2} \mathrm{O}_{\text {LCP, sat }}$-isopleths in summer when considering the stratospheric background. However, even during winter the structure is still significantly different from the transit time distribution in Fig. 3. 

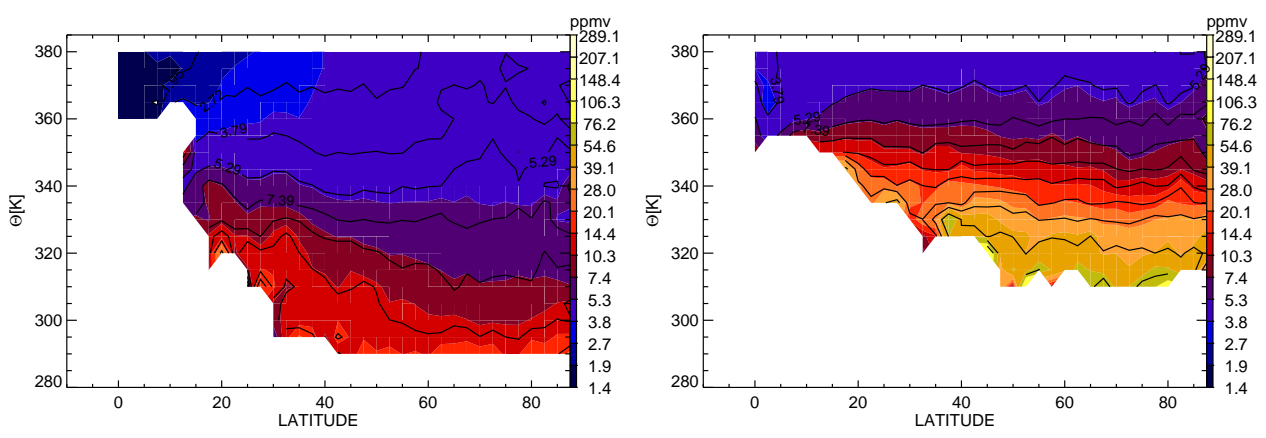

Fig. 9. Mean saturation mixing ratio of the TST trajectories according to their LCP and non-TST trajectories, assuming 5 ppmv $\mathrm{H}_{2} \mathrm{O}$ for stratospheric background for northern winter (left) and summer (right), colours as in Fig. 8. Contours show the $\mathrm{H}_{2} \mathrm{O}_{\mathrm{LCP}}$, sat from Fig. 8 for comparison.
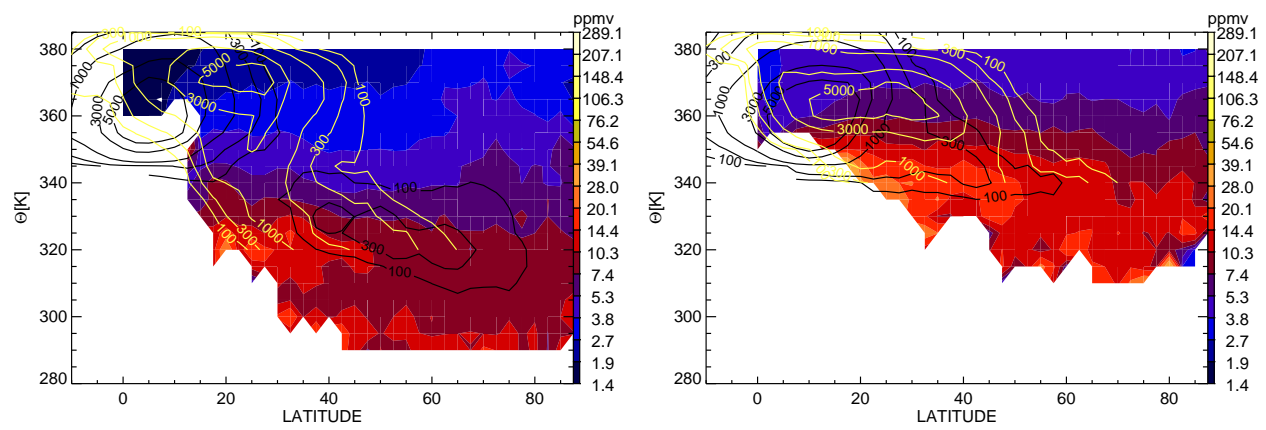

Fig. 10. Mean saturation mixing ratio from TST trajectories neglecting TST-events below $\Theta=320 \mathrm{~K}$ (winter, left) and $\Theta=340 \mathrm{~K}$ (summer, right), colours as in Fig. 8. Black and yellow contours indicate the locations of LCP and TST, respectively, for these subsets of TST trajectories (number in $2.5^{\circ} \times 5 \mathrm{~K}$-bins).

To estimate an upper boundary for extratropical TST based on $\mathrm{H}_{2} \mathrm{O}$ one tries to determine the location where $\mathrm{H}_{2} \mathrm{O}$ starts to increase above its stratospheric background values, which occurs at low $\mathrm{H}_{2} \mathrm{O}$ levels and high isentropes. To test the robustness of $\mathrm{H}_{2} \mathrm{O}_{L C P}$, sat particularly at highest isentropes to TST at the extratropical tropopause, we excluded TST-trajectories with $\Theta_{\mathrm{TST}}<320 \mathrm{~K}$ during winter and $\Theta_{\text {TST }}<340 \mathrm{~K}$ during summer, when the tropopause at mid to high latitudes is found at higher isentropes. The thresholds where chosen from Fig. 8 to be located roughly between the tropopause at mid latitudes and the 5 ppmv contour.

Figure 10 shows the resulting distributions for $\mathrm{H}_{2} \mathrm{O}_{L C P}$, sat and the locations of TST and LCP for the remaining TST trajectories. Comparing to the full set of TST-trajectories (Fig. 8) the location of the isopleths with lowest $\mathrm{H}_{2} \mathrm{O}_{L C P}$, sat (e.g. the location of $\mathrm{H}_{2} \mathrm{O}_{L C P}$, sat $=10$ ppmv) are hardly affected when neglecting TST-trajectories at low $\Theta_{\text {TST. }}$. In summer the structure of $\mathrm{H}_{2} \mathrm{O}_{\mathrm{LCP}}$, sat remains virtually unchanged down to $\Theta=330 \mathrm{~K}$, which illustrates the strong effect of exchange in the subtropics for the $\mathrm{H}_{2} \mathrm{O}_{L C P}$, sat ${ }^{-}$ structure in the LMS. Note also the large number of TST trajectories entering the LMS in the subtropics, which are dehydrated in the TTL region. The bimodal distribution for dehydration during winter remains, which indicates, that these trajectories undergo a TST at $\Theta_{\mathrm{TST}}>320 \mathrm{~K}$, and become subsequently dehydrated at higher latitudes and lower isentropes. Figure 10 clearly indicates that the lowest values of $\mathrm{H}_{2} \mathrm{O}_{L C P}$,sat $<10 \mathrm{ppmv}$, which might serve as an upper boundary to indicate extratropical TST are hardly affected by TST across the extratropical tropopause. An analysis using $\mathrm{H}_{2} \mathrm{O}$ as a proxy for TST is mainly sensitive to temperature variations at the (sub-)tropical LCP in the region where $\mathrm{H}_{2} \mathrm{O}_{\mathrm{LCP} \text {, sat }}$ is above typical stratospheric values.

\subsection{Transit time and $\mathrm{CO}$ distribution}

The conclusion that a mixing layer exists, that follows the local dynamical tropopause was based on CO-observations during the SPURT-project (Hoor et al., 2004; Engel et al., 2006), which investigated the UTLS region over Europe over two years. One of the key findings that led to this conclusion was the distinct structure of $\mathrm{CO}$, which exhibits a pronounced "kink" when it is displayed as a function of potential temperature difference $(\Delta \Theta)$ relative to the local dynamical tropopause approximated by the $2 \mathrm{PVU}$-surface. To link the results of our trajectory calculations directly to the 

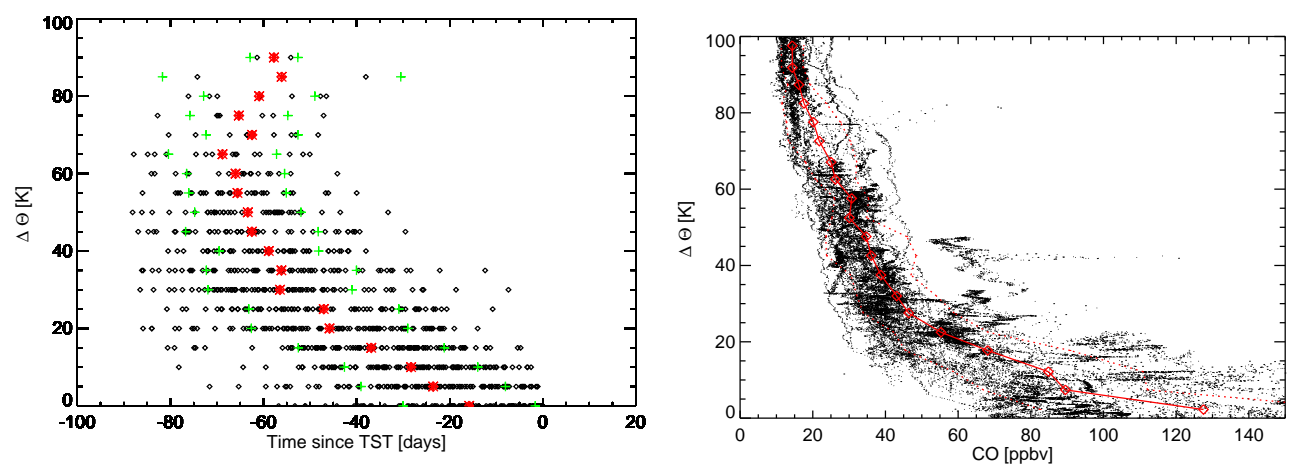

Fig. 11. Left: Profiles of transit times since last tropopause crossing as a function of potential temperature relative to the $2 \mathrm{PVU}$ surface $\left(\Delta \Theta\right.$ for latitudes $>45^{\circ} \mathrm{N}$ over Europe $\left(20^{\circ} \mathrm{W}-10^{\circ} \mathrm{E}\right)$. Red symbols indicate the mean, green the $1-\sigma$ standard deviation about the mean. Right: CO profiles over Europe as measured from various aircraft campaigns between 1998 and 2004. Red lines indicate the mean, dashed: $1-\sigma$ standard deviation. Both plots are for winter conditions over Europe.

measurements we focus on the European sector as defined in Fig. 11. For each grid point where a trajectory was initialized, we plotted the vertical profile of the times since TST $\left(t_{\mathrm{TST}}\right)$ in the same way as in Hoor et al. (2004) using $\Delta \Theta$ as vertical coordinate. The resulting distribution is shown in Fig. 11, where each black dot indicates the transit time of an individual TST-trajectory. Although a large variation of transit times at a given $\Delta \Theta$ level is found, an increase with larger distances from the tropopause is evident. Moreover, the mean transit time shows a "kink" at $\Delta \Theta=30 \mathrm{~K}$, which is very similar to the observation during SPURT (compare Fig. 6b in Hoor et al., 2004).

A direct comparison to $\mathrm{CO}$ data from various airborne campaigns during winter over Europe reveals a structure similar to mean profile of transit times (Fig. 11). A rapid decrease of $\mathrm{CO}$ directly above the local tropopause and a distinctly smaller gradient above $\Delta \Theta=30 \mathrm{~K}$ becomes evident. The local photochemical lifetime of $\mathrm{CO}$ in the tropopause region on the order of two months roughly matches the trajectory transit times. This gives a strong indication that the observed CO structure (the "kink") is a result of a change in the transit times since TST (i.e. $t_{\text {TST }}$ ). For summer CO as well as $t_{\text {TST }}$ show a similar transition around $\Delta \Theta=30 \mathrm{~K}$ and $t_{\text {TST }}$ indicates a shift to shorter times as evident from Fig. 3. In both seasons the transition is relatively well pronounced for $C O$ and appears around $\Delta \Theta=25 \pm 5 \mathrm{~K}$ above the local tropopause, where $\mathrm{CO}$ has decreased to $40 \mathrm{ppbv}$. The profile of $t_{\text {TST }}$ shows the gradient change almost at the same distance to the 2 PVU surface at $\Delta \Theta=30 \mathrm{~K}$. A perfect agreement cannot be expected since the high resolution $\mathrm{CO}$ measurements between 1998-2003 are compared to $t_{\mathrm{TST}}$ which has been obtained from the gridded ECMWF operational data for 2008. However, the good match between both data sets strikingly illustrates that the structure in both data sets is a climatological feature.

Interestingly the transit times seem to increase slightly at the highest levels, which might be related to recent tropo- spheric intrusions occurring above the location of the subtropical jet particularly during winter (Pan et al., 2009). The fact, that the "kink" in the CO observations appears at lower potential temperature levels above the local tropopause than indicated by the trajectories is most likely due to two main reasons: First, the uncertainties of the vertical wind, which drives the trajectories might introduce an offset to vertical velocities. Second, we only account for TST trajectories neglecting mixing with background, which dilutes the tropospheric CO fraction depending on the partitioning of stratospheric and tropospheric air. However, both effects lead to a shift of the "kink", but do not erase the vertical structure.

Note that the distribution of transit times does not show a sharp cut-off at 90 days nor is skewed particularly at any given higher $\Delta \Theta$-level. This indicates, that the calculation time of 90 days covered typical time scales for TST in the lowermost stratosphere and that the experiment is not limited by the 90 -day calculation time.

Thus, with regard to Fig. 11 it can be stated that the tropopause following mixing layer below $\Delta \Theta=30 \mathrm{~K}$ is the result of frequent and rapid exchange across the local tropopause with $t_{\mathrm{TST}}$ ranging from zero to 50 days during winter. Above $\Delta \Theta=30 \mathrm{~K} t_{\text {TST }}$ remains relatively constant at values exceeding 50 days on average. Consequently, the distribution of $\mathrm{CO}$ shows a similar structure since its abundance is controlled by the limited photochemical lifetime, which is of the same order of magnitude. The chemical structure of the extratropical tropopause region can therefore be regarded as a result of the change in $t_{\mathrm{TST}}$, which in turn is related to the location of the local tropopause.

The tropopause following character of transit times and their discontinuity at a given distance relative to the local dynamical tropopause is even more evident when using equivalent latitude to map $t_{\mathrm{TST}}$ (Fig. 12). The region of $t_{\mathrm{TST}}=40$ days as well as the fraction of TST events is compressed to a narrow band within $\Delta \Theta \approx 30 \mathrm{~K}$ (winter at latitudes $>40^{\circ} \mathrm{N}$, summer latitudes $>50^{\circ} \mathrm{N}$ ). The winter LMS 

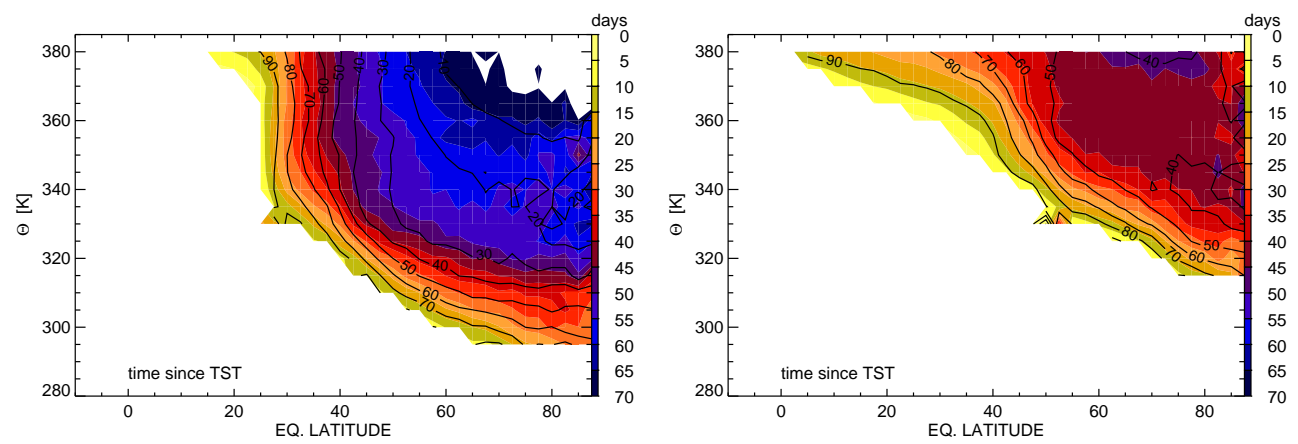

Fig. 12. Distribution of $t_{\text {TST }}$ projected to 1 February (left) and 1 August 2008 (right), respectively, as a function of equivalent latitude (compare Fig. 3). The gradient from yellow to blue indicates increasing $t_{\mathrm{TST}}$ with distance to the tropopause $\left(t_{\mathrm{TST}}=0\right)$. Note the even sharper transition of $t_{\mathrm{TST}}$ compared to Fig. 3 and the narrow band of $t_{\mathrm{TST}}<40$ days relative to the local tropopause. Contours show the fraction of TST-trajectories in percent.

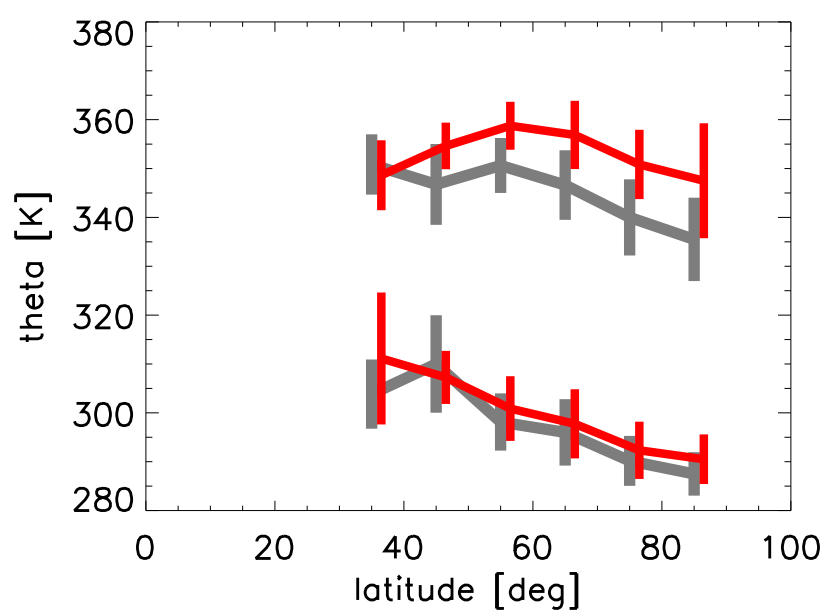

Fig. 13. Annual mean location of the upper and lower boundaries of a chemical defined ExTL. The boundaries are determined following the method in Hegglin et al. (2009) on the basis of $\mathrm{H}_{2} \mathrm{O}$ (red) and $\mathrm{CO}$ (grey) as observed from the ACE-FTS instrument.

contains a lower fraction of air that underwent recent TST compared to summer. Both findings are in agreement with (Berthet et al., 2007). The location of the thermal tropopause as shown in Fig. 3 falls within the band of $t_{\mathrm{TST}}<30$ days, indicating that the discontinuity is not a result of a tropopause mismatch.

The observations confirm the findings from the trajectory experiment indicating a lifetime dependent tracer distribution. In the case of $\mathrm{CO}$ the distribution mirrors the transport time since tropopause crossing at any point of the extratropical tropopause is independent of the potential temperature at the tropopause itself. Since the water vapour distribution reflects the combination of the temperature cycle at the subtropical tropopause, both tracers mirror different properties of cross tropopause transport.
There is also observational evidence of a seasonality of TST and the underlying time scales in the lowermost stratosphere. Hoor et al. (2005) concluded from CO measurements that during summer to autumn about $60 \%$ of the air in the lowermost stratosphere over Europe was of recent tropospheric origin (i.e. within the life time of $\mathrm{CO}$ ) decreasing to $30 \%$ during winter. Based on the analysis of bimodal age spectra in the lowermost stratosphere Bönisch et al. (2009) also deduced a significantly lower fraction of tropospheric air during winter/spring in the lowermost stratosphere than during summer with significantly lower transit times in summer compared to winter.

\subsection{Consequences for an ExTL boundary}

The structural differences between $\mathrm{H}_{2} \mathrm{O}_{L C P}$, sat and the distribution of $t_{\mathrm{TST}}$ deduced from the trajectory analysis become evident when analyzing correlations of $\mathrm{CO}-\mathrm{O}_{3}$ and $\mathrm{H}_{2} \mathrm{O}-\mathrm{O}_{3}$, respectively, following the method of Hegglin et al. (2009). The method determines the highest potential temperature $\Theta$ at which the respective correlation starts to deviate from the typical stratospheric "L-shape" or a defined background relationship. In the case of water vapour the upper boundary is equivalent to the hygropause in the extratropics since it is the layer where $\mathrm{H}_{2} \mathrm{O}$ exceeds its stratospheric background abundance. For $\mathrm{CO}$ the situation is different, since it has a finite lifetime and a canonical background correlation for the lowermost stratosphere cannot be clearly defined. The stratospheric part of $\mathrm{CO}-\mathrm{O}_{3}$ correlations is curved in the LMS and exhibits seasonally varying slopes. These seasonal variations can result from the seasonality in TST and particular transport time scales into and within the LMS (Fig. 3) altering the stratospheric background composition in the LMS of both $\mathrm{CO}$ and $\mathrm{O}_{3}$. Therefore a canonical $\mathrm{CO}-\mathrm{O}_{3}$ background branch in the LMS cannot be defined. However, using the criteria of Hegglin et al. (2009) allows us to obtain information on the aforementioned kink in $\mathrm{CO}$ and thus on the ExTL structure, although the derived $\Theta$ values are not 
independent from the choice of the criterion for the stratospheric background. Particularly the main difference found in the ExTL boundary derived from $\mathrm{H}_{2} \mathrm{O}-\mathrm{O}_{3}$ versus CO$\mathrm{O}_{3}$ (Hegglin et al., 2009) remains. It can be explained by the fact that $\mathrm{H}_{2} \mathrm{O}$ is long-lived in the stratosphere and controlled by temperature, while in contrast the stratospheric $\mathrm{CO}$ abundance depends on the location of the tropopause, which acts as a source for the LMS and the time for photochemical degradation. Therefore a different structure of any $\mathrm{CO}$ $\mathrm{O}_{3}$ defined boundary relative to $\mathrm{H}_{2} \mathrm{O}$ can be expected, even though $\Theta$ deduced from $\mathrm{CO}-\mathrm{O}_{3}$ may depend on the choice for the stratospheric background criterion.

An analysis of $\mathrm{CO}$ and $\mathrm{H}_{2} \mathrm{O}$ from ACE-FTS as in Hegglin et al. (2009) reveals these differences (Fig. 13). The figure shows the annual mean $\Theta$ bounds derived from the ACEFTS data on the basis of $\mathrm{CO}-\mathrm{O}_{3}$ and $\mathrm{H}_{2} \mathrm{O}-\mathrm{O}_{3}$, respectively, as a function of latitude and $\Theta$. The ExTL top deduced from $\mathrm{H}_{2} \mathrm{O}$ can be found at higher isentropes and is less tilted to isentropes than the $\mathrm{CO}$ based ExTL-top. The latter shows decreasing $\Theta$ values towards the pole and intersects the $\mathrm{H}_{2} \mathrm{O}$ ExTL top at low latitudes. This behaviour is a direct consequence of the different control mechanisms, which determine the respective stratospheric tracer abundance. For water vapour this is mainly $T_{\mathrm{LCP}}$ which transfers into a $\mathrm{H}_{2} \mathrm{O}_{\mathrm{LCP}}$, sat . The latter can be transported throughout the LMS since $\mathrm{H}_{2} \mathrm{O}$ has virtually no photochemical sink in the LMS. In contrast, the abundance of $\mathrm{CO}$ is affected by its finite lifetime and therefore $t_{\mathrm{TST}}$, which in turn is a function of distance to the local tropopause (Figs. 3 and 11). A CO-O 3 defined ExTL layer will therefore show a downward sloping structure with latitude as well, since the tropopause is at lower isentropes (and altitudes) at high latitudes.

\section{Conclusions}

The here presented evaluation of seasonal backward trajectories initialized within the lowermost stratosphere (LMS) allows us to explain the fundamental role of $t_{\mathrm{TST}}$ (i.e. the transit time since troposphere-to-stratosphere-transport TST) for the distribution and potential chemical impact of tracers in the LMS. On the basis of the structure of $t_{\mathrm{TST}}$ and the Lagrangian Cold Point (LCP) we can explain the distribution of $\mathrm{H}_{2} \mathrm{O}$ and $\mathrm{CO}$, which are two main tracers used to investigate tropospheric impact on the LMS. The analysis of the TST trajectories showed that the distribution of $t_{\mathrm{TST}}$ at a given day roughly follows the location of the tropopause, which is directly linked to the distribution of $\mathrm{CO}$. In fact any tracer with a finite lifetime and a tropospheric source and stratospheric sink will reflect this as long as the lifetime of the tracer is in the order of the underlying transport processes. In contrast, the temperature at the Lagrangian Cold Point $\left(T_{\mathrm{LCP}}\right)$ is distributed quasi-isentropically in the lowermost stratosphere, and its value controls the maximum saturation mixing for water vapour entering the LMS. It follows that the abundance of
$\mathrm{H}_{2} \mathrm{O}$ is fundamentally different from that of a tracer with a finite lifetime since the stratospheric abundance of both tracers are controlled by different processes.

The following aspects therefore have to be considered when investigating the extent of tropospheric influence in the extratropical stratosphere using $\mathrm{H}_{2} \mathrm{O}$ or $\mathrm{CO}$ :

1. The distribution of $t_{\mathrm{TST}}$, i.e. the time since last TST for each trajectory in generally follows the dynamical tropopause leading to larger mean transit times with increasing distance from the local tropopause. Thus, $t_{\mathrm{TST}}$ is a function of distance relative to the local tropopause.

2. The stratospheric $\mathrm{CO}$ distribution, which is observed to be different from that of $\mathrm{H}_{2} \mathrm{O}$ (see Fig. 1), mirrors the distribution of $t_{\text {TST }}$. Frequent mixing at the extratropical tropopause enhances $\mathrm{CO}$ in a finite layer, which is here shown to reflect the structure of the stratospheric residence time of the air parcels. As such the CO distribution indicates the extent of TST within a given time interval (the lifetime of $\mathrm{CO}$ ). The abundance of $\mathrm{CO}$ is determined by its finite lifetime convolved with the frequency of TST events: photochemical degradation in the stratosphere at far distances from the tropopause acts to slowly reduce its initial stratospheric entry value, which is solely determined by its tropospheric sources.

3. The water vapour structure in the extratropical lowermost stratosphere is strongly affected by the LCP in the tropical troposphere, which determines $\mathrm{H}_{2} \mathrm{O}_{L C P}$, sat for air parcels subsequently undergoing TST in the subtropics.

4. The location of LCP generally does not coincide with the location of TST. Both events can be separated by more than 20 days in time between $\Theta=315-360 \mathrm{~K}$ particularly during winter. Dehydration occurs mostly in the troposphere before the TST event.

5. $\mathrm{H}_{2} \mathrm{O}_{\mathrm{LCP}}$,sat is distributed quasi-isentropically in the LMS within less than 90 days and undergoes mixing within the stratosphere, thereby losing its relation to the TST event. Notably the hygropause in the LMS is determined by $\mathrm{H}_{2} \mathrm{O}_{\mathrm{LCP}}$, sat in the tropical troposphere and subsequent TST in the subtropics, rather than exchange in the extratropics.

The tropopause following mixing layer (or extratropical transition layer ExTL) as determined by Hoor et al. (2004) and confirmed from global observations by Hegglin et al. (2009) on the basis of CO can thus be regarded as a region which is characterized by frequent exchange and short transit times since tropopause crossing (Berthet et al., 2007). It thus exhibits a tropospheric chemical signature and strong coupling to the local tropopause as evident from high $\mathrm{CO}$ values and the $\mathrm{CO}_{2}$-seasonal cycle in phase with the local troposphere (Hoor et al., 2004; Sawa et al., 2008). At larger distances from the local tropopause the lowermost stratosphere 
is governed by larger transit times. Stirring and mixing processes within the stratosphere lead to a collapse of the relation between transit times and PV. Longlived tracers such as $\mathrm{H}_{2} \mathrm{O}$ are distributed quasi-isentropically, slowly descending under the influence of the Brewer-Dobson circulation. The strong seasonality of $\mathrm{H}_{2} \mathrm{O}_{L C P}$, sat, which is related directly to the LCP in the TTL and exchange in the subtropics leads to higher $\mathrm{H}_{2} \mathrm{O}$ abundances during summer. It has been suggested that the formation and strengths of the extratropical tropopause inversion layer (TIL) (Birner, 2006) is related to the stratospheric water vapour abundance (Randel et al., 2007). Our results would imply that the TIL at least during summer is partly a (sub-)tropically generated phenomenon.

Our results indicate that changes of tropical upper tropospheric temperatures will strongly affect $\mathrm{H}_{2} \mathrm{O}$ in the extratropical LMS, where it significantly contributes to the radiative budget (Forster and Shine, 1999) and therefore can be expected to have a strong impact on surface climate (Solomon et al., 2010).

Acknowledgements. Thanks go to Michael Sprenger for extracting the tropopause information from ECMWF. We thank the German Weather Service (DWD) and the Canadian Space Agency (CSA) for providing access to the ECMWF analyses and ACE-FTS data, respectively. The work of P.H. has been funded by the DFG project POMODORO. M.I.H. has been supported by the Canadian Foundation for Climate and Atmospheric Sciences and the CSA through the C-SPARC network.

Edited by: W. Lahoz

\section{References}

Appenzeller, C., Davies, H., and Norton, W.: Fragmentation of stratospheric Intrusions, J. Geophys. Res., 101, 1435-1456, 1996a.

Appenzeller, C., Holton, J. R., and Rosenlof, K. H.: Seasonal variation of mass transport across the tropopause, J. Geophys. Res., 101, 15071-15078, 1996b.

Berthet, G., Esler, J., and Haynes, P.: A Lagrangian Perspective of the tropopause and the ventilation of the lowermost stratosphere, J. Geophys. Res., 112, D18102, doi:10.1029/2006JD008295, 2007.

Birner, T.: Fine-scale structure of the extratropical tropopause region, J. Geophys. Res., 111, D04104, doi: 10.1029/2005JD006301, 2006.

Bönisch, H., Engel, A., Curtius, J., Birner, Th., and Hoor, P.: Quantifying transport into the lowermost stratosphere using simultaneous in-situ measurements of SF6 and $\mathrm{CO}_{2}$, Atmos. Chem. Phys., 9, 5905-5919, doi:10.5194/acp-9-5905-2009, 2009.

Bourqui, M. S.: Stratosphere-troposphere exchange from the Lagrangian perspective: a case study and method sensitivities, Atmos. Chem. Phys., 6, 2651-2670, doi:10.5194/acp-6-2651-2006, 2006.

Dessler, A. E., Hintsa, E. J., Weinstock, E. M., Anderson, J. G., and Chan, K. R.: Mechanism controlling water vapor in the lower stratosphere: "A tale of two stratospheres", J. Geophys. Res., 100, 23167-23172, 1995.
Engel, A., Bönisch, H., Brunner, D., Fischer, H., Franke, H., Günther, G., Gurk, C., Hegglin, M., Hoor, P., Königstedt, R., Krebsbach, M., Maser, R., Parchatka, U., Peter, T., Schell, D., Schiller, C., Schmidt, U., Spelten, N., Szabo, T., Weers, U., Wernli, H., Wetter, T., and Wirth, V.: Highly resolved observations of trace gases in the lowermost stratosphere and upper troposphere from the Spurt project: an overview, Atmos. Chem. Phys., 6, 283-301, doi:10.5194/acp-6-283-2006, 2006.

Fischer, H., Wienhold, F. G., Hoor, P., Bujok, O., Schiller, C., Siegmund, P., Ambaum, M., Scheeren, H. A., and Lelieveld, J.: Tracer correlations in the northern high latitude lowermost stratosphere: Influence of cross-tropopause mass exchange, Geophys. Res. Lett., 27, 97-100, 2000.

Fischer, H., de Reus, M., Traub, M., Williams, J., Lelieveld, J., de Gouw, J., Warneke, C., Schlager, H., Minikin, A., Scheele, R., and Siegmund, P.: Deep convective injection of boundary layer air into the lowermost stratosphere at midlatitudes, Atmos. Chem. Phys., 3, 739-745, doi:10.5194/acp-3-739-2003, 2003.

Forster, P. and Shine, K.: Stratospheric water vapour changes as a possible contributor to observed stratospheric cooling, Geophys. Res. Lett., 26, 3309-3312, 1999.

Fueglistaler, S. and Haynes, P.: Control of interannual and longerterm variability of stratospheric water vapor, J. Geophys. Res., 110, D24108, doi:10.1029/2005JD006019, 2005.

Fueglistaler, S., Wernli, H., and Peter, T.: Tropical troposphereto-stratosphere transport inferred from trajectory calculations, J. Geophys. Res., 109, D03108, doi:10.1029/2003JD004069, 2004.

Fueglistaler, S., Bonazzola, M., Haynes, P., and Peter, T.: Stratospheric water vapor predicted from the Lagrangian temperature history of air entering the stratosphere in the tropics, J. Geophys. Res., 110, D08107, doi:10.1029/2004JD005516, 2005.

Haynes, P. and Shuckburgh, E.: Effective diffusivity as a diagnostic of atmospheric transport, 2., Troposphere and lower stratosphere, J. Geophys. Res., 105, 22795-22810, 2000.

Hegglin, M. I., Brunner, D., Peter, T., Hoor, P., Fischer, H., Staehelin, J., Krebsbach, M., Schiller, C., Parchatka, U., and Weers, $\mathrm{U}$.: Measurements of $\mathrm{NO}, \mathrm{NO}_{\mathrm{y}}, \mathrm{N}_{2} \mathrm{O}$, and $\mathrm{O}_{3}$ during SPURT: implications for transport and chemistry in the lowermost stratosphere, Atmos. Chem. Phys., 6, 1331-1350, doi:10.5194/acp-61331-2006, 2006.

Hegglin, M., Boone, C., Manney, G., and Walker, K.: A global view of the extratropical tropopause transition layer from Atmospheric Chemistry Experiment Fourier Transform Spectrometer O3, $\mathrm{H}_{2} \mathrm{O}$, and CO, J. Geophys. Res., 114, D00B11, doi: 10.1029/2008JD009984, 2009.

Hegglin, M. I., Brunner, D., Wernli, H., Schwierz, C., Martius, O., Hoor, P., Fischer, H., Parchatka, U., Spelten, N., Schiller, C., Krebsbach, M., Weers, U., Staehelin, J., and Peter, Th.: Tracing troposphere-to-stratosphere transport above a mid-latitude deep convective system, Atmos. Chem. Phys., 4, 741-756, doi:10.5194/acp-4-741-2004, 2004.

Holton, J. R., Haynes, P. H., McIntyre, M. E., Douglass, A. R., Rood, R. B., and Pfister, L.: Stratosphere-troposphere exchange, Rev. Geophys., 33, 403-439, 1995.

Hoor, P., Fischer, H., Lange, L., Lelieveld, J., and Brunner, D.: Seasonal variations of a mixing layer in the lowermost stratosphere as identified by the $\mathrm{CO}-\mathrm{O}_{3}$ correlation from in situ measurements, J. Geophys. Res., 107, 4044, doi:10.1029/2000JD000289, 2002. 
Hoor, P., Gurk, C., Brunner, D., Hegglin, M. I., Wernli, H., and Fischer, H.: Seasonality and extent of extratropical TST derived from in-situ CO measurements during SPURT, Atmos. Chem. Phys., 4, 1427-1442, doi:10.5194/acp-4-1427-2004, 2004.

Hoor, P., Fischer, H., and Lelieveld, J.: Tropical and extratropical tropospheric air in the lowermost stratosphere over Europe: A CO-based budget, Geophys. Res. Lett., 32, L07802, doi:10.1029/ 2004GL022018, 2005.

James, P., Stohl, A., Forster, C., Eckhardt, S., Seibert, P., and Frank, A.: A 15-year climatology of stratosphere-troposphere exchange with a Lagrangian particle dispersion model: 2. Mean climate and seasonal variability, J. Geophys. Res., 108, 8522, doi:10.1029/2002JD002639, 2003.

James, R. and Legras, B.: Mixing processes and exchanges in the tropical and the subtropical UT/LS, Atmos. Chem. Phys., 9, 2538, doi:10.5194/acp-9-25-2009, 2009.

Konopka, P., Günther, G., Müller, R., dos Santos, F. H. S., Schiller, C., Ravegnani, F., Ulanovsky, A., Schlager, H., Volk, C. M., Viciani, S., Pan, L. L., McKenna, D.-S., and Riese, M.: Contribution of mixing to upward transport across the tropical tropopause layer (TTL), Atmos. Chem. Phys., 7, 3285-3308, doi:10.5194/acp-7-3285-2007, 2007.

Konopka, P., Grooss, J.-U., Ploeger, F., and Müller, R.: Annual cycle of horizontal in-mixing into the lower tropical stratosphere, J. Geophys. Res., 114, D19111, doi:10.1029/2009JD011955, 2009.

Krebsbach, M., Schiller, C., Brunner, D., Günther, G., Hegglin, M. I., Mottaghy, D., Riese, M., Spelten, N., and Wernli, H.: Seasonal cycles and variability of $\mathrm{O}_{3}$ and $\mathrm{H}_{2} \mathrm{O}$ in the UT/LMS during SPURT, Atmos. Chem. Phys., 6, 109-125, doi:10.5194/acp6-109-2006, 2006.

Krüger, K., Tegtmeier, S., and Rex, M.: Long-term climatology of air mass transport through the Tropical Tropopause Layer (TTL) during NH winter, Atmos. Chem. Phys., 8, 813-823, doi:10.5194/acp-8-813-2008, 2008.

Lacis, A. A., Wuebbles, D. J., and Logan, J. A.: Radiative forcing of climate by changes in the vertical distribution of ozone, J. Geophys. Res., 95, 9971-9981, 1990.

Lelieveld, J., Bregman, B., Arnold, F., Bürger, V., Crutzen, P. J., Fischer, H., Waibel, A., Siegmund, P., and van Velthoven, P. F. J.: Chemical perturbation of the lowermost stratosphere through exchange with the troposphere, Geophys. Res. Lett., 24, 603-606, 1997.

Liniger, M. and Davies, H.: Substructure of a MAP streamer, Q. J. Roy. Meteorol. Soc., 129, 633-651, doi:10.1256/qj.02.28, 2003.

Liu, Y., Fueglistaler, S., and Haynes, P.: The advectioncondensation paradigm for stratospheric water vapour, J. Geophys. Res., under revision, 2010.

Marti, J. and Mauersberger, K.: A survey and new measurements of ice vapor-pressure at temperatures between 170 and $250 \mathrm{~K}$, Geophys. Res. Lett., 20, 363-366, 1993.

Meijer, E., Bregman, B., Segers, A., and van Velthoven, P.F.J.: The influence of data assimilation on the age of air calculated with a global chemistry-transport model using ECMWF wind fields, Geophys. Res. Lett., 31, L23114, doi:10.1029/2004GL021158, 2004.

Monge-Sanz, B.M., Chipperfield, M.P., Simmons, A.J., and Uppala, S.M.: Mean age of air and transport in a CTM: Comparison of different ECMWF analyses, Geophys. Res. Lett., 34, L04801, doi:10.1029/2006GL028515, 2007.
Pan, L., Hintsa, E., Stone, E., Weinstock, E., and Randel, W.: The seasonal cycle of water vapor and saturation vapor mixing ratio in the extratropical lowermost stratosphere, J. Geophys. Res., 105, 26519-26530, 2000.

Pan, L., Randel, W., Gary, B., Mahoney, M., and Hintsa, E.: Definitions and sharpness of the extratropical tropopause: A trace gas perspective, J. Geophys. Res., 109, D23103, doi:10.1029/ 2004JD004982, 2004.

Pan, L. L., Randel, W. J., Gille, J. C., Hall, W. D., Nardi, B., Massie, S., Yudin, V., Khosravi, R., Konopka, P., and Tarasick, D.: Tropospheric intrusions associated with the secondary tropopause, J. Geophys. Res., 114, D10302, doi:10.1029/2008JD011374, 2009.

Pan, L.L.and Konopka, P. and Browell, E.: Observations and model simulations of mixing near the extratropical tropopause, J. Geophys. Res., 111, D05106, doi:10.1029/2005JD006480, 2006.

Ploeger, F., Konopka, P., Gunther, G., Groo, J., and Müller, R.: Impact of the vertical velocity scheme on modeling transport in the tropical tropopause layer, J. Geophys. Res., 115, D03301, doi: 10.1029/2009JD012023, 2010.

Randel, W. J., Wu, F., Gettelman, A., Russell III, J.M., Zawodny, J.M., and Oltmans, S.J.: Seasonal variation of water vapor in the lower stratosphere observed in Halogen Occultation Experiment data, J. Geophys. Res., 106, 14313-14325, 2001.

Randel, W. J., Wu, F., and Forster, P.: The extratropical tropopause inversion layer: Global observations with GPS data, and a radiative forcing mechanism, J. Atmos. Sci., 64, 4489-4496, 2007.

Sawa, Y., Machida, T., and Matsueda, H.: Seasonal variations of $\mathrm{CO} 2$ near the tropopause observed by commercial aircraft, J. Geophys. Res., 113, D23301, doi:10.1029/2008JD010568, 2008.

Schilling, T., Lübken, F.-J., Wienhold, F., Hoor, P., and Fischer, H.: TDLAS trace gas measurements within mountain waves over Northern Scandinavia during the POLSTAR campaign in early 1997, Geophys. Res. Lett., 26, 303-306, doi:10.1029/ 1998GL900314, 1999.

Shapiro, M. A.: Turbulent mixing within tropopause folds as a mechanism for the exchange of chemical constituents between the stratosphere and troposphere, J. Atmos. Sci., 37, 994-1004, 1980.

Shepherd, T. G.: Transport in the middle atmosphere, J. Meteor. Soc. Japan, 85B, 165-191, 2007.

Simmons, A., Uppala, S., Dee, D., and Kobayashi, S.: ERAInterim: New ECMWF reanalysis products from 1989 onwards, ECMWF Newsletter, 110, 25-35, 2006.

Solomon, S., Rosenlof, K. H., Portmann, R. W., Daniel, J. S., Davis, S. M., Sanford, T. J., and Plattner, G.-K.: Contributions of Stratospheric Water Vapor to Decadal Changes in the Rate of Global Warming, Science, 327, 1219-1223, doi:10.1126/ science.1182488, 2010.

Sprenger, M. and Wernli, H.: A northern hemispheric climatology of cross-tropopause exchange for the ERA15 time period (19791993), J. Geophys. Res., 108, 8521, doi:10.1029/2002JD002636, 2003.

Tegtmeier, S., Rex, M., Krüger, K., Wohltmann, I., and Schoellhammer, K.: Variations of the residual circulation in the northern hemispheric winter, J. Geophys. Res., 113, D16109, doi: 10.1029/2007JD009518, 2008.

Uppala, S., Dee, D., Kobayashi, S., Berrisford, P., and Simmons, A.: Towards a climate data assimilation system: Status update of ERAInterim, ECMWF Newsletter, 115, 12-18, 2008. 
Wang, P.: Moisture plumes above thunderstorm anvils and their contributions to cross-tropopause transport of water vapor in midlatitudes, J. Geophys. Res., 108, 4194, doi:10.1029/ 2002JD002581, 2003.

Wernli, H. and Bourqui, M.: A Lagrangian "1-year climatology" of deep cross-tropopause exchange in the extratropical Northern hemisphere, J. Geophys. Res., 107, 4021, doi:10.1029/ 2001JD000812, 2002.
Wernli, H. and Davies, H. C.: A Lagrangian based analysis of extratropical cyclones, 1, The method and some applications, Q. J. Roy. Meteorol. Soc., 123, 467-489, 1997.

Wirth, V. and Szabo, T.: Sharpness of the extratropical tropopause in baroclinic life cycle experiments, Geophys. Res. Lett., 34, L02809, doi:10.1029/2006GL028369, 2007. 